\title{
Lo colectivo, lo técnico y lo político: Algunos apuntes sobre la necesidad de la deliberación en la construcción de lo público*
}

\author{
Francisco Báez Urbina
}

Universidad Arcis, Santiago, Chile. Email: franciscobaezurbina@hotmail.com

Resumen: En este documento se intentará argumentar que los procesos de constitución de provisión de bienes públicos involucran necesariamente un problema de acción colectiva y que el diseño de políticas públicas son procesos de carácter esencialmente político y no técnico, como se promueve desde el neoliberalismo. De esta manera, para ser democráticos y pretendidamente no conflictivos deben ser necesariamente deliberativos.

Palabras clave: Acción colectiva, bienes públicos, movimientos sociales urbanos, democracia deliberativa.

\section{The collective, the technical and the political:} some notes on the need to deliberate in the construction of the public dimension

Abstract: This paper will attempt to argue that the process of constitution of provision of public goods necessarily implies a problem of collective action. In this context, the processes of policy-making are essentially a political issue, and not a technical one, as is promoted by neoliberalism. Thus, in aiming to be democratic and non-conflictive, processes must necessarily be deliberative.

Key words: Collective action, public goods, urban social movements, deliberative democracy.

\section{O coletivo, o técnico eo político: \\ algumas notas sobre a necessidade de deliberar na construção da dimensão pública}

Resumo: Este artigo tentará argumentar que o processo de constituição de provisão de bens públicos implica necessariamente um problema de ação coletiva. Neste contexto, os processos de formulação de políticas são essencialmente uma questão política, e não os técnicos, como é promovido pelo neoliberalismo. Desta forma, com o objectivo de ser um processo democrático e não-conflituoso, ele deve ser deliberativo.

Palavras-chave: ação coletiva, bens públicos, movimentos sociais urbanos, democracia deliberativa. 


\section{Introducción}

“Se trata de proponer, escuchar, concertar y cambiar la propia opinión a fin de formar en común una voluntad mancomunada”.

(Sieyes)

Desde una mirada analítica (Hedström y Swedberg, 1998; Boudon 1981; Elster 1996, 2007; Bowles \& Gintis, 2001; Lizón, 2007), sostenemos que lo social se constituye a partir de la puesta en operación -cooperativa o conflictiva- de los diferentes intereses -individuales o corporadosexistentes dentro del juego social, lo político se configura como el espacio de la resolución centralizada o descentralizada a algunas lógicas problemáticas de acción colectiva, ${ }^{1}$ y la deliberación de los diferentes agentes se considera (o se debiera considerar normativamente) como el ingrediente básico a la hora de definir los objetivos sociales útiles al colectivo en general. ${ }^{2}$ Intentaremos argumentar: (1) que los procesos de constitución de lo social pueden ser retratados a partir de la provisión de los denominados bienes públicos (en adelante BP), lo que involucra el problema estándar de la acción colectiva; (2) que el diseño de políticas públicas (como las territoriales, por ejemplo) son -aunque no lo parezcan- procesos de carácter esencialmente político y no técnico, como el neoliberalismo pretende señalar; y (3) que para ser democráticos y pretendidamente no conflictivos lo procesos de diseño de política deben ser necesariamente deliberativos. En este sentido, se parte de los supuestos de que (1) los actores involucrados representan intereses individuales o corporados orientados (según la Teoría de la Elección Racional enriquecida motivacionalmente o con explicaciones alternativas, ${ }^{3}$ en adelante TER, programa de base del marxismo analítico y la Nueva Economía Política) fundamentalmente al beneficio propio, y que (2) dichos intereses deben ser considerados como insumos de procesos de decisión y acción colectiva mayores, generales y que engloban a lo social o a lo nacional en su conjunto (la comunidad nacional, la economía nacional, la ciudad, por ejemplo). Esto es, la acción colectiva entendida en su sentido amplio, es decir, la acción colectiva entendida como la constitución de lo social o de la comunidad económico-política (en un contexto de base industrial fordista, por ejemplo), y considerando lo urbano como su dimensión espacial.

\section{La perspectiva analítica, la acción colectiva y la conformación de lo público}

Pero partamos de la definición del estilo en la argumentación. Para ello, descifremos los ejes propios de la sociología analítica. La sociología analítica es un programa de investigación social y política -o un estilo de hacerla- que busca explicar causalmente procesos sociales complejos diseccionándolos en sus componentes fundamentales. Según lo señalado en el "Manifiesto por una sociología analítica” del Grupo de Trabajo de Sociología Analítica de la Federación Española de Sociología FES (tam- 
bién en Aguiar et al, 2009), Peter Hedström, uno de sus principales valedores, sostiene que los rasgos característicos de la sociología analítica, serían: (1) "La precisión en las definiciones y la minimización de la ambigüedad, evitando los juegos de palabras supuestamente ingeniosos y estableciendo con nitidez el significado de los términos y conceptos utilizados"; (2) "La preocupación por la inteligibilidad racional del discurso y por el rigor lógico de la argumentación; (...) utiliza un discurso transparente y directo, auto disciplinado, evitando los recursos retóricos innecesarios que no aportan información alguna ni hacen progresar el argumento"; (3) "La actitud epistémica racionalista, contraria a toda pose relativista frívola"; (4) "La opción metodológica por la explicación causal en términos de mecanismos y micro fundamentos, y el intento de erradicación de las (...) "cajas negras" existentes en los discursos habituales de la ciencia social”; (5) "La necesidad de tomar en serio los progresos y descubrimientos de las ciencias contemporáneas, de atreverse a considerar su relevancia para las ciencias sociales, y de buscar la integración de éstas dentro de la gran república democrática de las ciencias (...)”; (6) "La formalización y el uso de modelos como herramientas útiles para la explicación científica, que aportan ventajas tales como disciplina, sistematicidad, exhaustividad, economía intelectual, ahorro de tiempo y esfuerzo, replicabilidad de resultados, y explicitación clara de supuestos”; y (7) “La exploración de las implicaciones normativas (...) a partir de la teoría social normativa contemporánea, unida, sin embargo, a la distinción nítida entre posturas ideológicas y posturas epistémicas o metodológicas, que evite convertir la ciencia social en un simple panfleto ideológico". ${ }^{4}$

Pues bien, de acuerdo a una perspectiva analítica, y para los acotados fines de este escrito, entenderemos lo social como el campo (público) que se constituye preferentemente por la acción intencional y corporada de distintos grupos, los que, poniendo en práctica sus decisiones y acciones (basadas en intereses: individuales o corporados, egoístas -basados en preferencias de naturaleza económica- $\mathrm{o}$ altruistas -basados en preferencias de naturaleza social-, de próximo o amplio alcance, de corto o largo plazo) junto a las de otros agentes instalados en el entorno territorial y temporal próximo o no tan próximo (que también pondrán en práctica las propias), irían contribuyendo a generar redes interdependientes de decisiones y de resultados esperados o no esperados -y observados o por observar. Todas ellas, configuradas en función de la búsqueda de resultados óptimos para cada parte (García Sobrecases, 2000).

Por otro lado, y si como bien sabemos, las categorías de lo público, de lo común, lo gratuito, lo colectivo, lo estatal, lo político, lo gubernamental, lo social, lo fiscal, no son lo mismo, sostenemos, desde la perspectiva analítica, que lo que está bajo la conformación de lo social (en abstracto) o lo estatal (su reglamentación formal), es la noción concreta de BP, un tipo especial de bien (un fallo de mercado) que, una vez producido, beneficiará a toda la comunidad, no sólo a los que pagaron el coste -material o inmaterial- de su provisión o implementación. En efecto, técnicamente los BP o externalidades (positivas o negativas), son bienes caracterizados por la no 
rivalidad y la no exclusión. En otras palabras, bienes que pueden ser consumidos paralelamente por un número indefinido de agentes, y que una vez provistos, producen, disfrute universal del cual, por definición, a nadie se puede excluir. Además de ello, generan externalidades en su entorno próximo difíciles de controlar desde mecanismos institucionales. ${ }^{5}$ El problema es que en ausencia de derechos de propiedad, este tipo de bienes, además de que comportan una alta complejidad en cuando a sus impactos y a los inter juegos de las externalidades que provocan, bajo los supuestos de la TER estándar, no generan incentivos para sostener sus propios procesos de provisión. En este contexto, el denominado problema de los BP (en adelante, el PBP) alude entonces a una estructura perversa de preferencias que caracteriza el intercambio entre agentes, y que -individualmente- tiende a generar no cooperación, propiciando resultados ineficientes o sub óptimos. Sin la existencia de incentivos necesarios para la cooperación, se dará el comportamiento free rider. Que no haya cooperación significará -entonces- la inexistencia de acuerdos de partida para compartir los costes. En efecto, el PBP alude a una estructura perversa de preferencias que caracteriza el intercambio económico o político entre agentes, y que individualmente tiende a generar no cooperación, propiciando, con ello, resultados ineficientes o sub óptimos. ${ }^{6}$ En tal sentido, si los BP en general son bienes de baja o nula exclusión (benefician potencialmente al conjunto de la comunidad) y si tienen baja o nula rivalidad (pueden ser consumidos simultáneamente por $n$ individuos), el problema teórico que plantean es el de la actitud recurrente de resistencia u oposición a la cooperación por parte de los agentes frente a sus procesos de suministro. ¿La razón?, desde la TER estándar los BP por sí mismos no generan incentivos a la cooperación, incluso en los casos en los que son de necesidad evidente y patente para la población tomada como conjunto. En otras palabras, el PBP es el problema de intercambio voluntario que se genera cuando, en lenguaje de juegos, la estrategia dominante (es decir, lo racional) es disfrutar colectivamente de los beneficios generados por éste, decidiendo individualmente no cooperar en el pago del coste asignado a su provisión. Lo que equivale a decir, por un lado, que lo que colectivamente es racional, individualmente no lo es; más bien, por el contrario, es completamente irracional. Y, a la inversa, lo que es colectivamente es irracional, es individualmente racional. Dicho en clave estrictamente económica: ninguna empresa estará dispuesta a pagar el coste de reducir su producción para subir el precio de un producto determinado, si el resto de las empresas (la competencia) no está dispuesto a asumir el mismo coste. De acuerdo a ello, el PBP es el problema de la no cooperación recurrente de individuos racionales ego centrados y auto interesados que, en el campo de la provisión de bienes de uso colectivo, pretenden gozar de la no exclusividad y la no universalidad de sus beneficios sin haber contribuido a su obtención. Eso es exactamente lo que prevé la teoría estándar cuando señala que, si teóricamente los BP son bienes de consumo no excluyente ${ }^{7}$ y de rivalidad baja o media, ${ }^{8}$ no existirán incentivos necesarios y/o suficientes para que los agentes cooperen en su provisión, situación que provocará que todos se comporten como free riders, es decir, como "viajeros gratuitos". En efecto, puesto que la gente puede consumirlos sin necesidad de pagar por ellos, en el campo de la provisión de 
BP habrá una tendencia (patrón ubicuo y persistente) a comportarse como un free rider, esperando que sean otros los que paguen los costes (sociales u otros) de su provisión para así poder beneficiarse de él gratuitamente. Ello, con la consecuencia inmediata de que el bien no se produzca o se produzca pero no en la calidad o en la cantidad demandada. De esta forma, el resultado será una provisión del bien en niveles sub óptimos, es decir, niveles ineficientes desde el punto de vista paretiano (una cantidad menor de la que se hubiera producido en el caso de que todos hubiesen "pagado"). De esta manera, los propios supuestos de la teoría económica estándar nos llevan tangencialmente al planteamiento de uno de los fallos del mercado característico de una situación de intercambio determinada. Es decir, por falta de cooperación individual, el Estado, en calidad de ente supra individual por definición, debe hacerse cargo de la provisión de bienes de consumo universal, es decir, de aquellos bienes que el mercado no es capaz de producir ni en la cantidad suficiente ni en la calidad deseada por los consumidores (sean bienes tangibles como una carretera o intangibles como la democracia liberal).

Pues bien, la presencia ubicua de esta estructura perversa de preferencias representa formalmente un problema de características e implicaciones centrales para la economía pública y la democracia contemporánea. ${ }^{9} \mathrm{Si}$ el individuo no va a ser excluido del consumo del bien en cuestión, y su estrategia dominante (la estrategia racional o que maximiza su bienestar personal), es claramente no cooperar, el problema de la gestión pública está servido. Así, por ejemplo, ningún agente corporado social o económico (conjunción de agentes individuales o corporados sectorialmente organizados) o barrio de la ciudad (como cúmulo de agentes individuales o corporados territorialmente organizados) estará dispuesto a financiar parte de los costes de la implementación de bienes que serán de utilidad colectiva, ${ }^{10} \mathrm{y}$ el bien no se producirá.

Como vemos, desde el utilitarismo estándar las consecuencias comportamentales obligadas aparejadas a la noción de BP son las categorías de acción colectiva y de no cooperación. Desde esta perspectiva, una acción colectiva es una acción emprendida por dos o más agentes (individuales o corporados) que, bajo el ánimo de procurarse beneficios compartidos, logran establecer y coordinar esfuerzos comunes. Por el contrario, un problema de acción colectiva se dará cuando, debido a que los agentes racionales carecen de incentivos para procurar la consecución de un bien colectivo, actúan en beneficio propio y en detrimento de resultados sociales deseables (Elster, 1991, 2006; Olson, 1992; Ostrom, 2000; Lizón, 2007). Consistirá, por tanto, en una situación de intercambio en la que, desde los mecanismos intencionales estándar de la teoría, es mejor para todos que algunos cooperen en la consecución de los objetivos comunes trazados sean estos cuales sean- a que nadie lo haga. Pero, desde la perspectiva de cada uno de los involucrados, aunque pueda ser mejor para todos que todos o algunos lo hagan a que nadie lo haga, siempre será mejor o más rentable no hacerlo, es decir, abstenerse de cooperar y que lo que haya que hacer para el bien de todos lo hagan otros. En escenarios descentralizados, dicho 
problema suele resolverse mediante una secuencia virtuosa de motivaciones individuales a la acción colectiva: utilitaristas, altruistas psicológicas, altruistas morales, etc. (Elster, 1996, 2007). En escenarios centralizados, sólo se resolverá mediante la acción de algún agente externo o principio de autoridad supra individual que decide por el colectivo de forma vinculante. Si la primera puede entenderse dentro de un orden ideal espontáneo, la segunda sólo podrá ser entendida desde una noción de necesidad de orden instituido que presuponga algún tipo de diseño institucional (Bowles, 2004). ${ }^{11}$

De acuerdo a ello, entonces, y antes de seguir avanzando, debemos precisar que la idea de lo público es utilizada laxamente aquí por la necesidad de promoción de la idea de lo universal a propósito de lo colectivo, y no por la necesidad técnica de utilizar las características propias y estrictas de los BP en el análisis (esto es, independiente del grado de exclusión o de rivalidad observado), lo que, en definitiva, sociopolíticamente involucrará que "todos debieran ser convocados a deliberar colectivamente sobre los resultados que un bien determinado -público- generará sobre todos".

\section{La necesidad de la deliberación en la conformación de lo público}

Pues bien, como sabemos, uno de los presupuestos básicos del ajuste neoliberal de las últimas tres décadas involucra la promoción y legitimación del imperativo técnico por sobre consideraciones de tipo político en la constitución de la política pública, lo que tiene a la base la usurpación -radicalizada- de la soberanía por parte de una elite tecnocrática - financiera especializada y refugiada en la legitimidad técnico - científica del discurso de la economía académica neoclásica (matematizada, formal, y ajena a importantes consideraciones políticas como, por ejemplo, las asimetrías de poder propias de la producción de lo social en su conjunto). En este sentido, el neoliberalismo asocia la función de la gestión de la democracia representativa como la función del managment en la gerencia privada: plantea un problema a resolver y encuentra una alternativa de solución en la soledad de su interesado liderazgo autocentrado y maximizador (vertical u horizontal). Es decir, no concibe que la diferencia de la presidencia del poder ejecutivo con la gerencia general de una empresa privada nacional o transnacional, es que, en un contexto democrático (inclusive el liberal), las soluciones a los problemas sociales se establecen colectivamente mediante algún tipo de mecanismo deliberativo (directo -democracia participativa roussoniana- o indirecto - democracia representativa liberal-), aunque no lo parezca.

"(...) hay que añadir la habitual desconfianza de la clase política (...) en la madurez del pueblo para decidir sobre los asuntos que de verdad le importan, como cuánto se gasta en políticas sociales: educación, sanidad, cultura, medio ambiente... Se ha llegado a decir que se trata de "cuestiones técnicas", que no son aptas para ser sometidas a referéndum, lo que viene a ser un eufemismo de que el "pueblo es idiota", por lo que revivimos aquella célebre máxima del 
despotismo ilustrado: "todo para el pueblo pero sin el pueblo", que reconvertida a dogma de la dictadura de mercado ilustrada vendría a ser algo así como "todo para los mercados pero sin el pueblo", lo cual evidencia la pérdida de legitimidad en el contexto neoliberal del pueblo como sujeto titular de la soberanía, pues soberano -aquí y hoy- es sólo quien goza del dominio del mercado" (Preciado Domènech, 2011).

En ese tenor, suponer que el instrumental técnico está en condiciones de proporcionar la única, mejor y, por tanto, indiscutida vía posible para la producción de BP (o bienes privados suministrados por el Estado como es el caso de la educación), es -por menos- ingenuo. Por el contrario, debemos decir que es evidente e ideológicamente interesado. Por definición, las políticas públicas (preferentemente las económicas, aunque también las sociales) favorecen a unos intereses y perjudican a otros, y, en la mayoría de los casos, los costes de las soluciones de política construidas se reparten inequitativamente entre los distintos grupos o estratos de la población (a nivel nacional, regional, etc.). ${ }^{12}$

Respecto de ello, entendemos la deliberación como ejercicio colectivo de discusión conjunta acerca de lo público ${ }^{13}$ que permita modificar las propias preferencias y reorientarlas hacia resultados colectivamente más beneficiosos, lo que nos lleva a pensar necesariamente en la noción desde diseño institucional (Pettit, 2003), y en la distinción entre la concepción positiva (libertad republicana como ausencia de dominación o no interferencia arbitraria) o negativa (libertad liberal como no interferencia) de la libertad, la democracia y los derechos sociales (Habermas, 1999). En palabras de Elster: "la toma colectiva de decisiones con la participación de todos los que han de ser afectados por la decisión o por sus representantes: esta es la parte democrática (...) y la toma de decisiones por medio de argumentos ofrecidos por y para los participantes que están comprometidos con los valores de racionalidad e imparcialidad: esta es la parte deliberativa" (Elster, 2001: 21). En definitiva, un modelo de democracia normativamente considerado en donde las decisiones colectivas (de gobierno sobre los asuntos colectivos) deben ser sustentadas en procesos de deliberación racional y pública, modelo que se contrapone necesariamente al modelo elitista de la agregación de preferencias individuales dadas del liberalismo (Gargarella, 1999) que señala que las preferencias sociales deben ser interpretadas por representantes que gestionen lo estatal. En efecto, a diferencia de lo que ocurre en el mercado como arreglo institucional de intercambio privado en donde el consumidor elije entre distintos cursos de acción que sólo difieren entre ellos respecto de como lo benefician a él personalmente, en la esfera de la política, los ciudadanos expresan sus preferencias respecto de estados que también afectarán a otros. Por ello, desde el republicanismo democrático, por ejemplo (que presenta una visión de la democracia no economicista y/o no pluralista), se sostiene que no debe confundirse el tipo de conductas apropiada para el mercado con la apropiada para la polis (Elster, 1990). 
Dentro de ello, y respecto de la necesidad de deliberación en clave territorial, por ejemplo, los movimientos de oposición ciudadana (en adelante, MOC), movimientos sociales que reaccionan oponiéndose a la implantación de un bien de uso colectivo determinado, los entendemos como indicadores de conflicto sectorial y territorial, y como parte de las diversas reacciones observables en el espacio cotidiano de producción de lo público (lo estrictamente ajeno a los derechos de propiedad). De acuerdo a ello, los MOC reflejarían las discrepancias existentes en lo social, por ejemplo, en el terreno de lo concerniente a la naturaleza de las decisiones gubernamentales construidas (objetivos trazados, grupos beneficiarios, etc.) o sobre las asimetrías de la estructura general de coste - beneficio que hay detrás de la provisión de un BP determinado (proceso de cooperación o de acción colectiva general o en sentido amplio, es decir, a escala nacional, por ejemplo): en nuestro caso la ciudad o la política social educativa, ${ }^{14}$ por ejemplo. Así, en términos concretos, la existencia de MOC en operación reflejará el desacuerdo existente en lo social sobre los términos de la acción colectiva general (a escala nacional -urbana- o internacional, dependiendo del bien de que se trate), es decir, los modos en que se constituye la "comunidad nacional" modernamente entendida o como se distribuye social o territorialmente la carga (los costes y/o las externalidades negativas) propia de la construcción de lo público. De esta manera, que haya acción colectiva opositora en la ciudad (movimientos sociales) significará que no hay acuerdo social (en términos sectoriales o territoriales) sobre el modo de definir los objetivos sociales, las prioridades sociales o la estructura general de costes presente en la provisión de BP de carácter sectorial o territorial.

En ese sentido, cuando se observa que la clase política se queja de la existencia de MOC que se levantan en contra de sus decisiones, acusándolos, por ejemplo, de insolidaridad o egoísmo por no querer un bien de uso colectivo de utilidad general en su comunidad (cualquier equipamiento urbano universalmente útil pero local o regionalmente no deseable, independiente del grado de cercanía de este), ello demuestra que viven aislados de la ciudadanía (la soberanía popular), y que creen fuertemente -por lo menos ante los medios- que el saber técnico de los representantes y sus asesores está por sobre las preferencias reveladas o no reveladas de sus representados. Como ya sabemos, la ciudadanía reacciona movilizándose cuando (a) no quiere "pagar" costes asociados (que "pague" otro agente o territorio: mecanismo NIMBY) ${ }^{15}$ (Báez Urbina, 2006), (b) cuando desconfía de las decisiones de los representantes (situación que se agrava cuando parecen ser decisiones inducidas por lobbies económicos asociados a especulativos y mezquinos intereses de clase expresados territorialmente), o (c) cuando vela por intereses más amplios, como los inter generacionales (o los de las generaciones futuras), por ejemplo (queremos otra solución técnica menos inicua: mecanismo NIABY) (Báez Urbina, 2009, 2011).

Al respecto, desde el punto de vista de la creación de modelos de gestión urbana participativa, y considerando que hay barrios urbanos, municipios y pueblos que la clase política sólo recuerda para poner en ellas lo 
que nadie quiere cerca de sus casas (lo que genera estigmatismo y malestar social localizado), creemos que se debieran promocionar modelos políticos deliberativos o de gerenciamiento gubernamental más horizontales que transparenten los procedimientos de decisiones y de asignación, haciendo -por ejemplo- mapas de equipamientos a nivel país y viendo cuáles tocan a tal o a cual territorio. En esa línea, y en el caso de las políticas de inversión territoriales, para un colectivo de referencia mayor y sus representantes pedir solidaridad a un colectivo menor (como una comunidad local o barrial de implantación de un BP determinado) debiera necesariamente implicar una compensación real o el equilibrio efectivo de cargas y beneficios en la gestión del territorio; esto es, por ejemplo, invertir en indemnizaciones reales, no enviar siempre los equipamientos indeseables a los barrios populares, o preservar sustentablemente recursos de uso común. Todo ello implicará pensar en la economía política del territorio (quien gana y quien pierde) y en la necesidad de transparentación de las afectaciones espaciales propias de la estructura global de coste - beneficio existente detrás de la construcción de lo urbano. Es decir, no otra cosa que mecanismos y modelos promotores de políticas de democracia espacial y de cohesión territorial.

En ese sentido, se precisa de la producción de instrumentos de planificación, coordinación y negociación entre todas las partes involucradas tendiendo en vistas la utilización permanente de procedimientos deliberativos más horizontales (instrumentos que pueden contribuir a crear una nueva cultura decisional y un nuevo tipo de proceso de decisiones en materia de infraestructuras y medio ambiente, por ejemplo) que transparenten y que vuelvan a evidenciar -después de 30 años de neoliberalismo extremo- que todo proceso de constitución social o urbano (y acá lo urbano sólo sirve de pretexto) no es más que el producto del conjunto de los intereses -individuales o corporados, egoístas o altruistas, de próximo o amplio alcance, de corto o largo plazo- puestos en el juego político y económico general. En ese sentido, recordemos, por un lado, que la política pública es sólo un instrumento de intervención en lo social de parte de un Estado operado por los gestores representantes de los intereses corporados de sectores sociales determinados (y que también presentan sus propios intereses, sean estos evidenciados o no: el riesgo moral); y por otro, que lo técnico es un imperativo de carácter eficientista que sólo es ubicable en la etapa de implementación de un instrumento de política, no de la definición de este ni de lo socialmente necesario. Lo socialmente necesario, es decir, la definición de la política pública a nivel conceptual, debe ser negociada y consensuada equilibradamente entre iguales a través de procesos racionales de discusión pública directos o indirectos. $\mathrm{O}$ por lo menos así debiera ser considerado normativamente. En efecto, el modelo tecno-autoritario no funciona en sociedades democráticas que ponen en práctica sus derechos y visibilizan sus intereses. En los actuales momentos de desarrollo de las sociedades avanzadas, la ciudadanía empoderada exige la existencia de procesos deliberativos que ofrezcan buena información sobre las diferentes alternativas y sus costes, y que se oigan todas las voces y todos los intereses involucrados; es decir, 
procesos de transparentación de intereses que complementen y mejoren la democracia representativa. De hecho, en ciertos escenarios de intercambio, "sólo se necesita información para producir cooperación", sostendrá Elster (1991a:49).

Sin duda que la existencia de conflictos obedecerá al choque de las distintas posiciones, intereses, capacidades e interpretaciones (diagnóstico sobre los problemas sociales y sobre las soluciones colectivas necesarias y correspondientes) realizados por los diferentes agentes intencionales corporados; y también será obvio que, las dificultades en la interpretación tendrá relación tanto con la multiplicidad de motivaciones a la acción colectiva observadas (racionales -egoístas- o irracionales -morales- desde el punto de vista de la racionalidad estándar de la teoría económica), con los horizontes temporales considerados, o las diferentes razones esgrimidas por los agentes en el campo de lo público, campo, por definición, de alta complejidad tanto en relación a su producción como a su gestión (Báez Urbina, 2009).

No obstante ello, dichas dificultades de interpretación se pueden lograr transparentar (al menos en cierto grado) inyectando información al proceso de toma de decisiones sobre las necesidades de inversión y la estructura general de costes involucrada; situación que acarreará, además, -y como externalidad positiva- tanto la incentivación de la participación social y política (como apenas señaláramos más arriba en palabras de Elster, la información diluye el Dilema del Prisionero), como la producción de una sensación ambiente de pertenencia (económica) a la comunidad de referencia; en este caso, la comunidad país. Nótese con ello que consideramos que (1) la participación social (los ánimos de "sentirse parte" del o de los procesos) está íntimamente ligada a la participación económica (el ser y sentirse parte de una unidad económica llamada Estado - nación); y (2) que ambas -junto a la participación política- deben considerarse como indicadores potentes desde el punto de vista de la necesidad del análisis de la acción colectiva global (en sentido amplio y de carácter nacional, por ejemplo) y de su promoción en un sentido virtuoso, horizontal y equitativo. Esto es, no otra cosa que la construcción más igualitaria de la propia comunidad / país.

¿De qué herramientas estamos hablando? Bajo la conjetura de probidad del agente, se ha de pensar en una interesante oferta de incentivos de carácter político, que transfirieran información privilegiada a la ciudadanía afectada a modo de compensación ex ante. Se trataría, por ejemplo, de mecanismos de incorporación formal de la parte afectada a espacios de diálogo o espacios orientados a promocionar la circulación de información $y$, con ello, el aumento de la confianza como elemento clave dentro del campo de la cooperación. De no hacerlo, se correrá el riesgo de generar compartimentos estancos en los que el diálogo entre actores es cada vez menor dentro del espacio social, algo que, ciertamente, va en detrimento del establecimiento y la mantención de la confianza entre agente gubernamental y ciudadanía. 
Por su parte, los foros participativos para establecer agendas compartidas de acción colectiva y para implementar actividades conjuntas, la generación de mecanismos de transparencia y responsabilidad compartidas, o los mecanismos de resolución de conflictos fidedignos e imparciales, acaban contribuyendo a la generación y la mantención de acciones colectivas exitosas e incrementando lateralmente la confianza en el gestor público de cara a acuerdos y compromisos de trabajo conjunto a mediado o largo plazo.

De manera complementaria, pensando en la transparencia territorial, por ejemplo, y como ingrediente que alimente los procesos deliberativos, sería preciso considerar otro aspecto importante: la necesidad de inversión en reputación por parte del gestor gubernamental en formato rendición de cuentas públicas (Báez Urbina, 2009). En efecto, uno de los principales factores que deben ser tomados en cuenta para la implantación de BP de carácter territorial es la confianza existente entre los miembros del colectivo o entre los miembros del colectivo y sus representantes (el capital social). Como sabemos, en grupos pequeños, o en lugares en los que las externalidades están relativamente localizadas, los miembros de la comunidad probablemente estén en mejor posición -mejor capacitados- para suministrar BP puesto que conocen mejor las condiciones locales que los agentes externos (tanto la estructura de incentivos individuales disponibles como otros factores que afectan a la capacidad para cooperar de esas comunidades: los grupos privilegiados de Olson). Por ello mismo, en grupos altamente heterogéneos -como los mayoritarios actualmente- se espera que dichas capacidades se vean mermadas debido a la complejidad de las redes de intereses y a la complejidad de las estructuras de preferencias disponibles (grupos latentes de Olson). No obstante ello, y aunque en este tipo de comunidades la intervención más útil puede ser la gestión de conflictos o la difusión de información pública, el historial previo de acciones colectivas satisfactorias entre particulares, o entre particulares y gestores, también pueden incidir en la mejora de las posibilidades de éxito futuras de la producción de instancias de diálogo ciudadanía - agente gubernamental. Así, incluso en ellas, y como sabemos a partir del de la lógica ilustrada a través Dilema del Prisionero Iterado, el contar con información relativa a comportamientos continuados en actividades prolongadas en el tiempo, si bien la iteración no incrementa la confianza, horizontalmente sí puede reforzar el grado de certeza de la cooperación de cara a intercambios futuros (Axelrod, 1984).

\section{A modo de conclusiones}

El documento tuvo por objetivo entregar -obviamente de manera sucinta- la particular visión de la constitución de lo social que se puede elaborar a partir de las consideraciones teóricas y metodológicas extraídas de las nociones de acción colectiva provistas por parte del marxismo analítico y de la sociología analítica. Las escuetas reflexiones acá expuestas emanaron, como subproducto, de un estudio sobre cooperación, acción 
colectiva y diseño institucional en la provisión de bienes de uso público de carácter urbano hecho recientemente a partir de la observación de algunos movimientos sociales opositores localizados en ciudades de Europa y América Latina.

Desde el punto de vista analítico, intentamos transmitir la idea de que la evolución de la configuración de la ciudad y del orden urbano subyacente pueden o deben entenderse o abordarse como un problema de acción colectiva territorialmente conformado (la conformación de la ciudad y de lo urbano como subproducto de la articulación de la cooperación o no cooperación entre agentes); y que la deliberación, como proceso de inyección de información, diluye el Dilema del Prisionero (dilema no cooperativo entre agentes egocentrados o racionales en términos estándar) previniendo la no cooperación en la conformación de la ciudad o la comunidad nacional entendida como un BP. Esto es, la inyección y la circulación de información al (y dentro del) sistema de intercambio, genera los vínculos de comunicación inter agente que requiere un proceso de gestión urbana de carácter democrático.

En ese sentido, la racionalidad técnica del saber experto (que viene en el ADN de la teoría económica estándar: la economía académica como manto técnico sofisticado que vela y encubre las asimetrías de poder y lo político) invisibiliza la racionalidad política que hay detrás (o debajo) de los procesos de inversión pública y subsume la racionalidad democrática (interjuego deliberativo -o no- de los principios e intereses sociales corporados) presente en la definición social de lo colectivamente necesario. Lo técnico debe entenderse como un aspecto crucial aunque complementario y sólo secundario (posterior) en la secuencia propia de los procesos de decisión/inversión, y no un imperativo necesariamente definitorio respecto de la naturaleza de las decisiones por tomar y que necesariamente son (o debieran ser) de carácter colectivo (competen al colectivo y no tan sólo al agente gubernamental y a sus propios intereses corporados). Como vemos, acá necesariamente asociamos lo político a la gestión conjunta y deliberada (de deliberación) de lo colectivo, donde lo técnico se hace necesario -una vez tomada la decisión- como un aspecto vinculado sólo a la consecución de los procesos e instrumentos que aseguren la calidad y la cantidad de los resultados esperados por el colectivo, y que el agente (los representantes), por mandato soberano, eficiente y probamente debe cumplir. 


\section{Notas}

* Una versión acotada de este trabajo fue presentada en el Grupo de trabajo 2: "La expansión del espacio público: sociedad civil, movimientos sociales y acción colectiva”, del Congreso Chileno de Sociología y Encuentro Pre ALAS Chile: "Sociología y Sociedad en Chile: Escenarios y diálogos contemporáneos”, efectuado en Valparaíso, Chile, abril del 2011. Preparado como notas o apuntes de investigación generados a partir de Báez Urbina, 2009. Dicha investigación obtuvo el financiamiento de diversas fuentes de financiamiento tanto en España como en Chile. Nos referimos a la Fundación Jaume Bofill y la agencia AGAUR de la Generalitat de Catalunya en España, y -en Chile- a uno de los programas de financiamiento pre doctorales coordinados por CONICYT para la realización de estudios de postgrado en el extranjero.

${ }^{1}$ Esto, tanto en los casos en los cuales el problema de la acción colectiva se resuelve de manera centralizada (preferentemente democracia representativa indirecta de tipo liberal), o descentralizada (una democracia de tipo más directo o deliberativo tal vez más republicana).

${ }^{2}$ Donde lo social está necesariamente incrustado en la esfera de lo económico y al revés. Ver comentarios sobre diseño institucional y teoría de la elección racional de Pettit en Goodin, 2003.

${ }^{3}$ A veces ajenas al discurso racional estándar de la economía neoclásica.

4 “Manifiesto por una sociología analítica” del Grupo de Trabajo de Sociología Analítica de la Federación Española de Sociología FES.

5 "Un mercado competitivo - el arquetipo de las instituciones privadas - es en si mismo un BP. Una vez que se genera un mercado competitivo los individuos pueden entrar y salir libremente, ya sea que contribuyan o no con el costo de generarlo y mantenerlo. Ningún mercado puede existir por mucho tiempo sin instituciones subyacentes que lo mantengan. En escenarios de campo, más que existir en mundos aislados, las instituciones públicas y privadas con frecuencia están entretejidas y dependen una de la otra” (Ostrom, 2000:43).

${ }^{6}$ Que no haya cooperación significa que no hay "acuerdos para compartir los costes y cada individuo tiene que cargar con todo el coste de cualquier aumento de la cantidad del bien colectivo” (Chamberlain, 1991:158).

${ }^{7}$ Universal. Coste de exclusión alto: crecen en la medida en que se sume un nuevo consumidor a los beneficios reportados.

${ }^{8}$ En el caso de los bienes públicos impuros, la calidad y la cantidad decrece a medida que son consumidos por una unidad adicional.

${ }^{9}$ Esto en circunstancias de la necesidad de provisión de bienes colectivos en situaciones de ausencia (contribución voluntaria) o presencia (contribución obligada) de un ente centralizado de toma de decisiones.

${ }^{10}$ En el plano territorial: bienes de utilidad universal como vías urbanas, servicios públicos o territoriales en general. 
11 “.... diferencia de lo que ocurre en el intercambio de bienes privados, las decisiones (en la provisión de BP) forman siempre parte de un proceso de decisión colectiva, que cabe considerar que es de tipo político, por el cual se seleccionan las preferencias de algunas personas, se imponen las elecciones reveladas por las mismas como decisión de la sociedad y se producen los fines o resultados que aquellas decisiones comportan (...) o la libertad para que las empresas contaminen en perjuicio de los deseos de algunos ciudadanos de respirar aire limpio, o regulación de la contaminación en prejuicio de las ganancias de los empresarios y en beneficio de quienes dan prioridad a las condiciones de la respiración (...) hay siempre en la política un elemento de consenso y uno de coerción” (Colomer, 1991:19).

${ }^{12}$ A propósito de la reciente exigencia de parte de la UE de modificar la estructura institucional española para limitar el gasto público: "La limitación del déficit y del endeudamiento públicos no es un dogma. Es un instrumento de política económica que pueden servir a finalidades diversas. En un determinado contexto, su contención puede contribuir a la buena salud de las finanzas y a un fortalecimiento democrático. Por ejemplo si se acompaña de políticas fiscales progresivas, que reduzcan la dependencia del crédito externo, o si se cierra el paso de manera firme al endeudamiento especulativo del sector privado. Pero en un contexto recesivo como el actual, en el que ninguno de los grandes partidos está realmente dispuesto a impulsar estas medidas, lo más probable es que la obsesión por eliminar, y no simplemente por contener el déficit, acabe por servir a objetivos menos nobles: la privatización de servicios públicos, el recorte de derechos a los más vulnerables o la reducción drástica del autogobierno en diferentes escalas, algo que de hecho ya está ocurriendo” (Pisarello, 2011).

${ }^{13} \mathrm{O}$ algún mecanismo que asegure algún grado de esta.

${ }^{14}$ Aunque, en realidad, y como ya señaláramos, la educación es un BP especial denominado bien privado suministrado por el Estado.

${ }^{15}$ Los mecanismos son tipos de explicaciones sobre la formación de preferencias y sus estados agregados, y aportan micro fundamentos a las explicaciones causales e intencionales de los fenómenos sociales. No obstante ello, no son leyes ni tampoco descripciones, es decir, admiten comportamientos anómalos dentro del modelo (Elster, 1995; Lizón, 2007). 


\section{Bibliografía}

Aguiar, F. (comp.) (1991), Intereses individuales y acción colectiva, Pablo Iglesias, Madrid, España.

Ídem (2006), “Libertad, justicia y juegos”, Documento de trabajo 1206, Instituto de Estudios Sociales Avanzados de Andalucía, Córdoba, España.

Aguiar, F., De Francisco, A. y Noguera, J. A. (2009), "Por un giro analítico en sociología”, en Revista Internacional de Sociología, Vol. 67, № 2, mayoagosto.

Axelrod, R. (1984), La evolución de la cooperación. El dilema del prisionero y la teoría de juegos, Alianza, Madrid, España.

Baez Urbina, F. (2006), Bienes públicos y comportamiento no cooperativo: La oposición ciudadana a los centros de atención a drogodependientes en Cataluña. Trabajo de Investigación UAB, Barcelona, España.

Ídem (2009), El problema de la acción colectiva y los movimientos de oposición ciudadana a la provisión de bienes de uso colectivo: El trazado del AVE a su paso por Barcelona, un caso relevante de estudio, Tesis para optar al grado de doctor en sociología, UAB, Barcelona, España.

Ídem (2011), “Acción colectiva y diseño urbano. Notas sobre las oposiciones a la provisión de uso colectivo”, Revista Polis n²8, Santiago de Chile.

Boudon, R. (1981), La lógica de lo social. Una introducción al análisis sociológico, RIALP Madrid, España.

Bowles, S. (2004), Microeconomics, behavior, institutions and evolution. Princeton University Press, USA.

Bowles, S. y Gintis, H. (2001), “¿Ha pasado de moda la igualdad? El hommo reciprocans y el futuro de las políticas igualitarias”, en Gargarella, R. y Ovejero, F. (comp.) Razones para el socialismo, Paidós, Barcelona, España.

Colomer, J. (comp.) (1991), Lecturas de teoría política positiva, Instituto de Estudios Fiscales, Ministerio de Economía y Hacienda, Madrid, España.

Domènech, A. (1991), "Elster y las limitaciones de la racionalidad”, en Elster, J. Domar la suerte, Paidós, Barcelona, España.

Ídem (2002a), “Individuo, comunidad y ciudadanía”, en Rubio-Carracedo, J., et al.Retos pendientes en ética y política, Trotta, Madrid, España.

Ídem (2002b), “Algunos enigmas de la racionalidad económica”, en 
Chomsky, N. y García, J. (comps.) Los límites de la globalización, Ariel, Barcelona, España.

Ídem (2004), El eclipse de la fraternidad. Una revisión republicana de la tradición socialista, Crítica, Barcelona, España.

Downs, A. (1973), Teoría Económica de la Democracia, Aguilar, Madrid, España.

Chamberlain, J. (1991), “La provisión de bienes colectivos como función del tamaño del grupo”, en Colomer, J. (comp.) Lecturas de teoría política positiva, Instituto de Estudios Fiscales, Ministerio de Economía y Hacienda, Madrid, España.

Elster, J. (1989), "Reflexiones sobre marxismo, funcionalismo y teoría de juegos”, en Roemer, J. El marxismo: una perspectiva analítica, FCE, Méxi$\mathrm{CO}, \mathrm{DF}$.

Ídem (1990), “The Market and the Forum”, en Elster, J. y Hylland, A. (ed.), Foundations of Social Choice Theory, Cambridge University Press, Cambridge, UK.

Ídem (1991a), “Racionalidad, moralidad y acción colectiva”, en Aguiar, F. (comp.) Intereses individuales y acción colectiva, Fundación Pablo Iglesias, Madrid, España.

Ídem (1991b), Domar la suerte, Paidós, Barcelona, España.

Ídem (1995), Psicología política, Gedisa, Barcelona, España.

Ídem (1996), Tuercas y tornillos. Una introducción a los conceptos básicos de las ciencias sociales, Gedisa, Barcelona, España.

Ídem (1997), Egonomics, Gedisa, Barcelona, España.

Ídem (2001), “Introducción”, en Elster, J. (comp.), La democracia deliberativa, Gedisa, Barcelona, España.

Ídem (2006a), El cemento de la sociedad. Las paradojas del orden social, Gedisa, Barcelona, España.

Ídem (2006b), Raison et raisons, Leçons Inaugurales du Collège de France, Collège de France / Fayard, Paris.

Ídem (2007), Explaining social behavior: more nuts and bolts for the social science, Cambridge University Press, Cambridge, UK.

Gargarella, R. (1999), Las teorías de la justicia después de Rawls. Un breve manual de filosofía política, Paidós, Barcelona, España. 
Gargarella, R. y Ovejero, F. (comp.), Razones para el socialismo, Paidós, Barcelona, España.

Gintis, H. et al. (2005), Moral sentiments and material interests: the foundations of cooperation in economic life, MIT Press, Cambridge, Massachusetts, USA.

Gigerenzer, G. (2008), Decisiones instintivas: la inteligencia del inconsciente, Ariel, Barcelona, España.

Granovetter, M. (1991), “Modelos de umbral de conducta colectiva”, en Aguiar, F. (comp.) Intereses individuales y acción colectiva, Pablo Iglesias, Madrid, España.

Goodin, R. (comp.), (2003), Teoría del diseño institucional, Gedisa, Barcelona, España.

Habermas, J. (1999), “Tres modelos normativos de democracia”, en La inclusión del otro. Estudios de teoría política, Paidós, Barcelona, España.

Hardin, R (1991), “La acción colectiva y el dilema del prisionero”, en Colomer, J. (comp.) Lecturas de teoría política positiva, Instituto de Estudios Fiscales, Ministerio de Economía y Hacienda, Madrid, España.

Hedström, P. y Swedberg, R. (1998), Social mechanisms, an analytical approach to social theory, Cambridge University Press, Cambridge, UK.

Jordana, J. (2006), “Las asociaciones de intereses y la acción colectiva”, en Caminal Badia, M. (Comp.) Manual de ciencia política, Tecnos, Madrid, España.

Linares, F., (2007), "El problema de la emergencia de normas sociales en la acción colectiva. Una aproximación analítica”, Revista Internacional de Sociología, vol. LXV, No 46, Instituto de Estudios Sociales Avanzados de Andalucía, Córdoba, España.

Lizon, A., (2007), La otra sociología, una saga de empíricos y analíticos, Montesinos / coedición UNAM, México, DF.

Mari-Klose, P. (2000), “Elección racional”, Cuadernos metodológicos $N^{o}$ 29, CIS, Madrid, España.

Miller, L. (2004a), “Acción colectiva y modelos de racionalidad”, Revista Estudios Fronterizos, Universidad Autónoma de Baja California, Enero junio, año/vol. 5, Nº9, Mexicali, México.

Noguera, J. (2003), “¿Quién teme al individualismo metodológico? Un análisis de sus implicaciones para la teoría social”, Papers 69, Departamento de Sociología, Universidad Autónoma de Barcelona, Barcelona, España. 
Olson, M. (1992), La lógica de la acción colectiva. Bienes públicos y la teoría de grupos, LIMUSA, Noriega Editores. México, DF.

Ostrom, E. (2000), El gobierno de los bienes comunes. La evolución de las instituciones colectivas, UNAM / CRIM / FCE, México, DF.

Ovejero, F., Martí, J. L. y Gargarella, R. (comp.) (2004), Nuevas ideas republicanas. Autogobierno y libertad, Paidos, Barcelona, España.

Paramio, L. (2005), “Teorías de la decisión racional y la acción colectiva”, en Sociológica $\mathrm{N}^{\circ}$ 57, Universidad Autónoma Metropolitana, Azcapotzalco, año 20, enero-abril, México, DF.

Pettit, P. (2003), “Diseño institucional y elección racional”, en Goodin, R. (comp.) (2003) Teoría del diseño institucional, Gedisa, Barcelona, Espaก̃a.

Saiegh, S. y Tommasi, M. (comp.) (1998), La nueva economía política: racionalidad e instituciones, Eudeba, Buenos Aires.

SepúlvedaA, M., Baez Urbina, F. y Montenegro, M. (2008), No en la puerta de mi casa: Implantación no conflictiva de dispositivos de drogodependencias, Grup Igia, Barcelona, España.

Schelling, T., (1989), Micromotivos y macroconductas, FCE, México, España.

\section{Recursos electrónicos utilizados}

Preciado Domènech, C. (2011), “Todo para el pueblo, pero sin el pueblo”, en revista electrónica Sin Permiso: http://www.sinpermiso.info/textos/ index.php?id=4387 Página consultada el 06/09/2011.

Pisarello, G. (Entrevista) (2011), “Reino de España: una (contra) reforma constitucional servil”, en revista electrónica Sin Permiso: http:// www.sinpermiso.info/textos/index.php?id=4398 Página consultada el 06/ 09/2011.

Recibido: 15.09.2011

Aceptado: 25.07.2012 